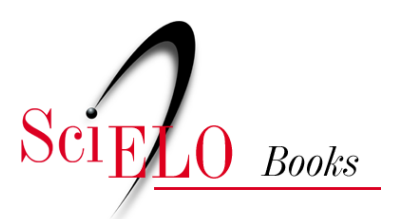

\title{
18 Tribo Astereae Cass.
}

\author{
Aristônio M. Teles \\ Gustavo Heiden \\ Angelo A. Schneider
}

TELES, A.M., HEIDEN, G., and SHNEIDER, A.A. Tribo Astereae Cass. In: ROQUE, N. TELES, A.M., and NAKAJIMA, J.N., comp. A família Asteraceae no Brasil: classificação e diversidade [online]. Salvador: EDUFBA, 2017, pp. 139-147. ISBN: 978-85-232-1999-4.

https://doi.org/10.7476/9788523219994.0020.

All the contents of this work, except where otherwise noted, is licensed under a Creative Commons Attribution 4.0 $\underline{\text { International license. }}$

Todo o conteúdo deste trabalho, exceto quando houver ressalva, é publicado sob a licença Creative Commons Atribição $\underline{4.0}$.

Todo el contenido de esta obra, excepto donde se indique lo contrario, está bajo licencia de la licencia Creative Commons Reconocimento 4.0. 


\title{
TRIBO ASTEREAE CASS.
}

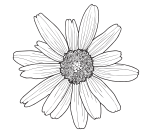 \\ Aristônio M. Teles \\ Gustavo Heiden \\ Angelo A. Schneider
}

Astereae emergiu como um grupo monofilético em inúmeros estudos filogenéticos (BROUILLET et al., 2009; PANERO; FUNK, 2008). A tribo compreende 18 subtribos, 222 gêneros, cerca de 3.100 espécies e apresenta distribuição cosmopolita (BROUILLET et al., 2009; NESOM; ROBINSON, 2007). Na América do Sul, ocorrem 31 gêneros e cerca de 740 espécies (NESOM, 1994e). Os representantes da tribo são geralmente caracterizados pelas anteras ecaudadas e ecalcaradas (Figura 13E), ramos do estilete das flores estaminadas ou bissexuadas triangulares ou lanceolados e com tricomas coletores abaxialmente (Figura 13F) (BROUILLET et al., 2009).

\section{Descrição}

Ervas a arbustos, ocasionalmente pequenas árvores ou trepadeiras, monoicas ou dioicas. Folhas alternas ou rosuladas, raro opostas. Capitulescência corimbiforme, paniculiforme ou capítulos solitários. Capítulos disciformes, discoides ou radiados; receptáculo geralmente epaleáceo, raramente paleáceo nos capítulos pistilados. Flores do raio 1-multisseriadas, pistiladas, corola liguliforme ou tubuloso-filiforme, amarela, branca, lilás ou rósea; flores do disco bissexuadas ou estaminadas, corola tubulosa, amarela ou esbranquiçada; anteras com base obtusa, truncada ou levemente auriculada, apêndice do conectivo curto, ovalado 
ou lanceolado; estilete das flores bissexuadas ou estaminadas com ramos triangulares ou lanceolados, apêndices apicais estéreis, linhas estigmáticas laterais, tricomas coletores distribuídos na face abaxial dos ramos do estilete. Cipselas com ápice truncado, atenuado ou rostrado, 2-multicostadas, epiderme uniestratificada com células espessadas em 3 dos seus lados (espessamento de parede em forma de “U”), glabras ou pilosas; pápus 1-3-seriado, cerdoso, escamiforme ou ausente, persistente ou caduco.

No Brasil, Astereae está representada por 9 subtribos, 18 gêneros e 247 espécies, das quais 137 são endêmicas, sendo que a maior diversidade é encontrada nas regiões Sudeste e Sul. Dentre os gêneros mais representativos na flora do Brasil, podemos citar: Baccharis L. (incluindo Baccharidastrum Cabrera, Baccharidiopsis G.M. Barroso e Heterothalamus Less., como sinônimos conforme Heiden \& Pirani, 2016), representado por 179 espécies, das quais 115 são endêmicas e cuja distribuição é majoritariamente extra-amazônica; Conyza L., com 15 espécies, a maioria ruderais; e Noticastrum DC., com 8 espécies, distribuídas principalmente em campos, restingas e vegetação secundária no Sul e Sudeste. Algumas espécies como Conyza bonariensis (L.) Cronquist, C. primulifolia (Lam.) Cuatr. \& Lourteig, C. sumatrensis (Retz.) E. Walker, Egletes viscosa Less., Solidago chilensis Meyen e Symphyotrichum squamatum (Spreng.) G.L. Nesom são de ampla valência ecológica e frequentemente encontradas como ruderais. Representantes de Astereae são encontrados na figura 15.

\section{Chave de identificação para os gêneros de Astereae no Brasil}

1. Capítulos disciformes ou discoides ................................................................. 2

1'. Capítulos radiados a inconspicuamente radiados........................................ 7

2. Capítulos disciformes ...................................................................................... 3

2'. Capítulos discoides ................................................................................ 6

3. Folhas paralelinérveas; flores pistiladas 1-seriadas; cipselas cilíndricas, 5-costadas ........................................................................................... Apopyros

3'. Folhas peninérveas ou reticulinérveas; flores pistiladas multisseriadas; cipselas comprimidas, 2-costadas ...................................................................... 4 
4. Brácteas involucrais 3-nervadas; cipselas com ápice truncado; pápus 1-seriado (Figura 13H) Conyza

4'. Brácteas involucrais 1-nervadas; cipselas rostradas ou apenas atenuadas no ápice; pápus 1-3-seriado 5

5. Cipselas apenas atenuadas no ápice; pápus 1(2-3)-seriado ......... Exostigma 5’. Cipselas rostradas; pápus 2(3)-seriado (Figura 13K) Podocoma

6. Brácteas involucrais 3-seriadas; capítulos com flores funcionalmente estaminadas; capítulos com flores pistiladas ou ainda capítulos com flores bissexuadas; cipselas fusiformes (Figura 13G).................................. Baccharis 6'. Brácteas involucrais 4-seriadas; capítulos com flores sempre bissexuadas; cipselas ovoides, comprimidas ou prismáticas (Figura 13J) Grindelia

7. Flores do raio neutras Baccharis

7’. Flores do raio pistiladas 8

8. Flores do disco funcionalmente estaminadas ................................................. 9

8'. Flores do disco bissexuadas .................................................................. 13

9. Cipselas cilíndricas a fusiformes, 4-10-costadas ......................... Baccharis

9'. Cipselas comprimidas, 2-costadas ........................................................... 10

10. Folhas pinatilobas ou pinatissectas ………………................................. 11

10'. Folhas inteiras ou denteadas .............................................................. 12

11. Lobos linear-espiniformes ......................................................... Sommerfeltia

11'. Lobos oblongos ou obovados ................................................ Plagiocheilus

12. Flores do raio 1(2)-seriadas; cipselas oblanceoloides a elípticooblanceoloides; pápus 2-3-seriado, esbranquiçado............................. Inulopsis 12'. Flores do raio 3-4-seriadas; cipselas obcônicas; pápus 1-seriado, amareloavermelhado. Asteropsis

13. Cipselas sem pápus (Figura 13I) ....................................................... Egletes

13'. Cipselas com pápus ................................................................................... 14

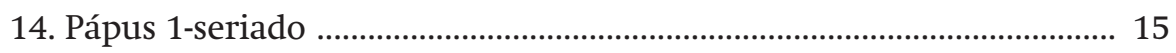

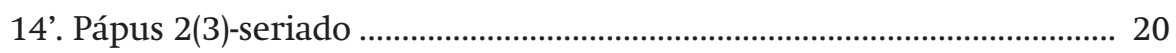


15. Pápus formado por 3-18 cerdas (Figura 13J) ou aristas rígidas e caducas Grindelia

15’. Pápus formado por mais de 20 cerdas capilares e persistentes 16

16. Flores do raio curtamente liguliformes, ou seja, com o limbo da corola mais curto que o estilete e nunca ultrapassando o comprimento das flores do disco Conyza 16'. Flores do raio longamente liguliformes, ou seja, com o limbo da corola mais longo que o estilete e sempre ultrapassando o comprimento das flores do disco.

17. Capitulescências corimbiformes; receptáculo fimbriado; cipselas elipsoides, comprimidas, 2-costadas Leptostelma 17'. Capítulos solitários ou dispostos em capitulescências paniculiformes; receptáculo alveolado; cipselas oblongo-obovoides a obcônicas, não comprimidas, 5-12-costadas 18

18. Plantas escaposas; lâmina foliar filiforme a linear-oblanceolada; capítulos solitários Neja 18'. Plantas folhosas até a capitulescência; lâmina foliar lanceolada a oblanceolada; capitulescências paniculiformes 19

19. Ramos secundários da capitulescência patentes e escorpioides; flores do raio amarelas; cipselas oblongo-obovoides, 5-costadas Solidago 19'. Ramos secundários da capitulescência ramificados; flores do raio brancas ou lilás; cipselas obcônicas, 10-12-costadas Symphyotrichum

20. Folhas com margem profundamente 3-lobadas apicalmente; pápus rubro Microgyne 20’. Folhas com margem íntegra, serreada ou denteada; pápus esbranquiçado

21. Cipselas cilíndricas, 16-26-costadas Noticastrum

21'. Cipselas comprimidas, 2-costadas 22 
22. Plantas geralmente escaposas com folhas basais normalmente dispostas em roseta; cipselas rostradas; pápus com cerdas de tamanhos iguais entre si (Figura 13K) Podocoma

22'. Plantas folhosas até a capitulescência; cipselas com ápice truncado; pápus com série externa curta com cerdas escamiformes e série interna mais longa com cerdas capilares.

Hysterionica

\section{Literatura recomendada}

BARROSO, G. M. Compositae - subtribo Baccharidinae Hoffmann: estudo das espécies ocorrentes no Brasil. Rodriguésia, Rio de Janeiro, v. 28, n. 40, p. 3-273, 1976.

BARTOLI, A.; TORTOSA, R. D. Revisión de las espécies sudamericanas de Grindelia (Asteraceae: Astereae). Kurtziana, v. 27, n. 3, p. 327-359, 1999. BRAZIL FLORA GROUP- BFG. Growing knowledge: an overview of seed Plant diversity in Brazil. Rodriguésia, Rio de Janeiro, v. 66, n. 4, p. 10851113, 2015.

BONIFACINO, J. M.; SANCHO, G.; MARCHESI, E. A new combination in Asteropsis (Compositae: Astereae), and a synopsis of the genus. Brittonia, Bronx, v. 61, n. 1, p. 1-7, 2009.

BROUILLET, L. et al. Astereae. In: FUNK, V. A et al. Systematics, evolution, and biogeography of Compositae. Vienna: IAPT, 2009. p. 587-629.

CABRERA, A. L. El género Hysterionica en el Uruguay y en la República Argentina. Notas del Museo de La Plata, La Plata, v. 11, n. 53, p. 349-359, 1946.

ESPINAR, L. A. Las espécies centroargentinas de Hysterionica (Compositae). Darwiniana, Buenos Aires, v. 22, n. 4, p. 537-549. 1980.

HEIDEN, G.; BAUMGRATZ, J. F. A.; ESTEVES, R. L. Baccharis subgen. Molina (Asteraceae) no estado do Rio de Janeiro, Brasil. Rodriguésia, Rio de Janeiro, v. 63, n. 3, p. 649-687, 2012. 
HEIDEN, G., IGANCI, J. R. V.; MACIAS, L. F. N. Baccharis sect. Caulopterae (Asteraceae, Astereae) no Rio Grande do Sul, Brasil. Rodriguésia, Rio de Janeiro, v. 60, n. 4, p. 943-983, 2009.

HEIDEN, G.; PIRANI, J. R. Novelties towards a phylogenetic infrageneric classification of Baccharis (Asteraceae, Astereae). Phytotaxa, Auckland, v. 289, n. 8, p. 285-290, 2016.

HEIDEN, G.; PIRANI, J. R. Taxonomy of Baccharis subgen. Tarchonanthoides (Asteraceae: Astereae: Baccharidinae), a group from the southeastern South American grasslands and savannas. Phytotaxa, Auckland, v. 241, n. 1, p. 1-70, 2016.

MULLER, J. Systematics of Baccharis (Compositae - Astereae) in Bolivia, including an overview of the genus. Systematics Botany Monographs, [S.1.], v. 76, p. 1-339, 2006.

NESOM, G. L. Apopyros (Asteraceae: Astereae), a new genus from southern Brazil, Argentina, and Paraguay. Phytologia, Huntsville, v. 76, p. 176-184, $1994 a$.

NESOM, G. L. Comments on Microgynella, Sommerfeltia, and Asteropsis (Asteraceae: Astereae). Phytologia, Huntsville, v. 76, p. 101-105, 1994b.

NESOM, G. L. Inulopsis synopsis (Asteraceae: Astereae). Phytologia, Huntsville, v. 76, p. 115-124, 1994c.

NESOM, G. L. Separation of Neja (Asteraceae: Astereae) from Hysterionica. Phytologia, Huntsville, v. 76, p. 168-175, 1994 d.

NESOM, G. L. Subtribal classification of the Astereae (Asteraceae). Phytologia, Huntsville, v. 76, p. 193-274, 1994e.

NESOM, G .L.; ROBINSON, H. Tribe Astereae Cass. In: KADEREIT, J. W.; JEFFREY, C. (Ed.). The Families and Genera of Vascular Plant: v. VIII: Flowering Plants Eudicots: Asterales. Berlin: Springer, 2007. p. 284-342.

PANERO, J. L.; FUNK, V. A. The value of sampling anomalous taxa in phylogenetic studies: major clades of the Compositae revealed. Molecular Phylogenetics and Evolution, Orlando, v. 47, n. 2, p. 757-782, 2008. 
SANCHO, G. Exostigma, a new genus of Astereae (Compositae) from Southern South America. Systematic Botany, Kent, v. 37, n. 2, p. 516-524, 2012.

SANCHO, G.; BONIFACINO, J. M.; Pruski, J. F. Revision of Microgyne (Asteraceae: Astereae), the correct name for Microgynella. Systematic Botany, Kent, v. 31, n. 4, p. 851-861, 2006.

SANCHO, G.; HIND, D. J. N.; PRUSKI, J. F. Systematics of Podocoma (Asteraceae: Astereae): a generic reassessment. Botanical Journal of Linnean Society, London, v. 163, n. 4, p. 486-513, 2010.

SCHNEIDER, A. A.; MODELSKI, V.; BOLDRINI, I. I. Hysterionica (Asteraceae: Astereae) para o Brasil. Rodriguésia, Rio de Janeiro, v. 64, n. 3, p. 597-606, 2013.

SOLBRIG, O. T. The South American species of Erigeron. Contributions from the Gray Herbarium of Harvard University, Cambridge, v. 191, p. 3-82, 1962. TELES, A. M.; SOBRAL, M.; STEHMANN, J. R. Synopsis of Leptostelma (Asteraceae: Astereae). Compositae Newsletter, Stockholm, v. 46, p. 1-6, 2008. ZARDINI, E. M. Revisión del género Noticastrum (Compositae-Astereae). Revista del Museo de La Plata, La Plata, v. 13, p. 313-424, 1985. Seccion Botanica. 


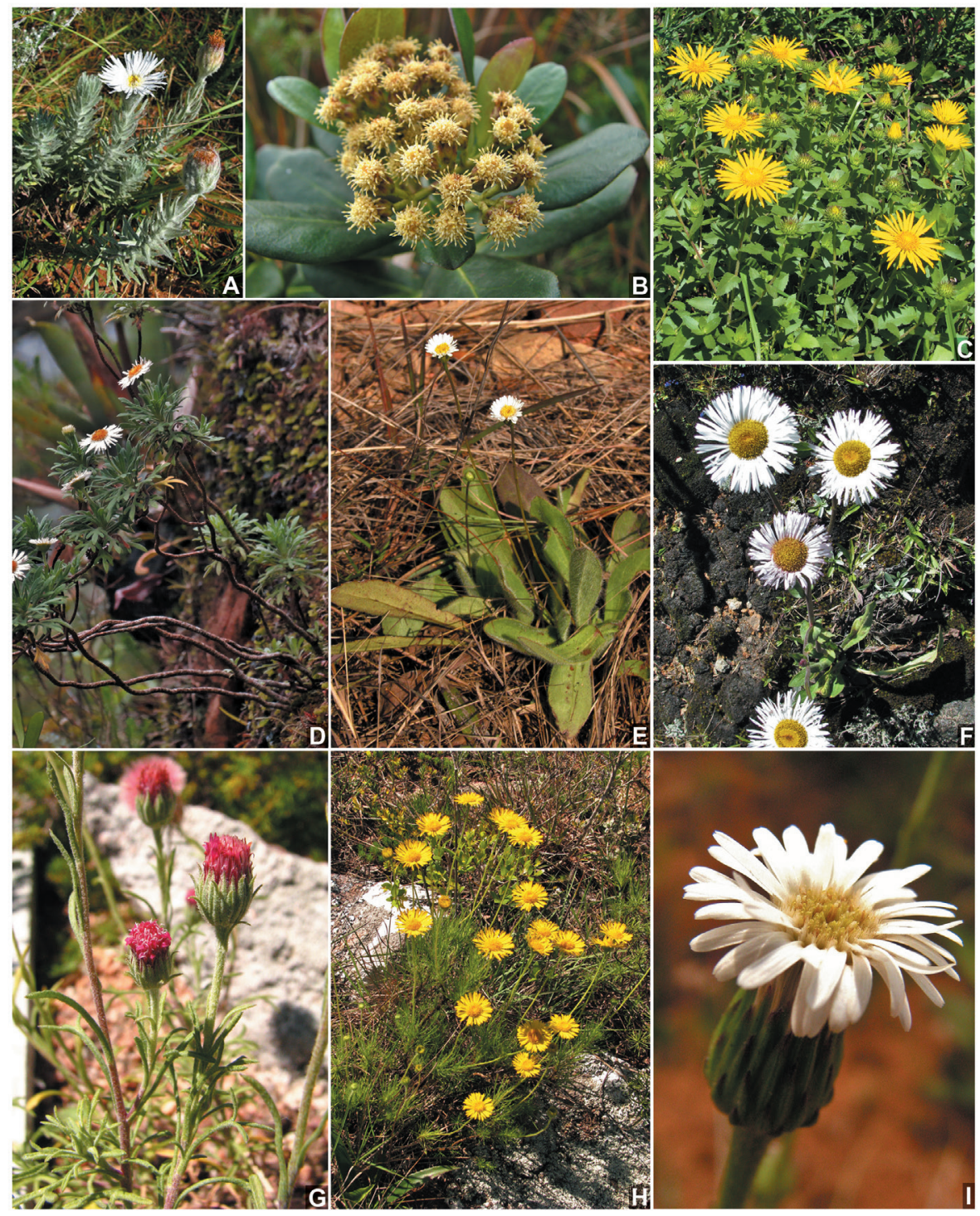

Figura 15. Astereae. A. Asteropsis megapotamica (Spreng.) Marchesi et al.; B. Baccharis macrophylla Dusén; C. Grindelia puberula Hook. \& Arn.; D. Hysterionica pinnatiloba Matzenb. \& Sobral; E. Inulopsis scaposa (DC.) O. Hoffm.; F. Leptostelma camposportoi (Cabrera) A.M. Teles \& Sobral; G. Microgyne trifurcata Less.; H. Neja filiformis (Spreng.) Nees; I. Podocoma bellidifolia Baker. 